\title{
SOME TOXIC EFFECTS OF VANADIUM PENTOXIDE
}

\author{
BY \\ H. WYERS \\ From Murex Ltd., Rainham, Essex
}

\begin{abstract}
Chemistry
Vanadium is a silvery-white metal of specific gravity 5.96 , melting-point $1710^{\circ} \mathrm{C}$., atomic weight $50 \cdot 95$, atomic volume $9 \cdot 3$, and atomic number 23 . The name is derived from that of the Scandinavian goddess Vanadis (Parkes and Mellor, 1939). It is rarely encountered in its pure state owing to difficulties in production consequent upon its tendency to oxidation. In Mendeléef's Periodic Table the atomic number of 23 places it in the A Sub-Group of Group V, with niobium, tantalum and proactinium. The last-named substance has radio-active properties. From the electronic configurations of the atoms in members of this subgroup it is evident that they are transition elements, since the penultimate electron group is incomplete and is in process of filling up. As transition elements, they are characterized by very variable valencies, the formation of highly coloured ions, are paramagnetic and have marked catalytic power.

Four oxides are known: hypovanadous oxide (VO or $\mathrm{V}_{2} \mathrm{O}_{2}$ ), vanadous oxide or vanadium trioxide $\left(\mathrm{V}_{2} \mathrm{O}_{3}\right)$, hypovanadic oxide $\left(\mathrm{VO}_{2}\right.$ or $\left.\mathrm{V}_{2} \mathrm{O}_{4}\right)$ and vanadic oxide or vanadium pentoxide $\left(\mathrm{V}_{2} \mathrm{O}_{5}\right)$. Hypovanadous oxide is a black powder. With acids it produces lavender-coloured solutions of hypovanadous salts from which caustic alkalies precipitate hypovanadous hydroxide, $\mathrm{V}(\mathrm{OH})_{2}$, one of the most powerful reducing agents known. Vanadous oxide is also a black powder and its salts are green in solution. Hypovanadic oxide forms blue solutions of vanadyl salts. Vanadium pentoxide is a yellowish red powder which is sparingly soluble in water. The basic properties of vanadium oxides diminish as the oxygen part of the molecule increases and the higher oxides exhibit acidic as well as basic properties.
\end{abstract}

\section{Manufacture}

The ores are distributed mainly in Peru, South Africa and Rhodesia, and occur as carnotite (potassium uranyl vanadate), patronite (impure vanadium sulphide) and vanadinite. In countries where the ores are not found, petroleum residues form the main sources. Three groups of raw materials are used in the plant about to be considered: (1) soot from oil burning liners, (2) furnace residues from oil refineries and (3) slags from the production of ferro-vanadium. The soot is ground and extracted with caustic soda solution and filtered.
The filtrate contains the bulk of the vanadium as sodium vanadate. The filter cake is mostly carbon but contains some sodium vanadate which is recovered. The furnace residues are fused with soda ash. The roast is crushed, the dust containing about 15 per cent. $\mathrm{V}_{2} \mathrm{O}_{5}$, and extracted with water and filtered. Sodium vanadate is present in the liquor. Slags are crushed, dried, ground the dust containing about 10 per cent. $\mathrm{V}_{2} \mathrm{O}_{5}$ and roasted with soda ash. The roast is then crushed, ground, extracted with water and filtered. The liquor contains sodium vanadate. The sodium vanadate liquors are alkaline. They are neutralized with sulphuric acid and filtered to remove small proportions of alumina and silica. The last substance is apt to be present from the firebrick in the raw material. Sulphuric acid is again added to the neutralized liquors to precipitate vanadium, mainly as the hydrated $\mathrm{V}_{2} \mathrm{O}_{5}$. Filtration, drying, roasting and crushing complete the process. The oxide is reduced to ferro-vanadium by the alumino-thermite process. Dust arises mainly from the crushing of oxide and in the plant under consideration is now entirely a closed operation.

\section{Uses}

The chief uses of vanadium are to raise the hardness and malleability of steel and to increase its fatigue-resisting properties. For example, it is said that $\frac{1}{2}$ per cent. of vanadium will raise the tensile strength of a sample of steel from $7 \frac{1}{2}$ to 13 tons per square inch. This property therefore commends its use to manufacturers of motor cars, Diesel engines and tools. The non-ferrous alloys are very hard and are resistant to atmospheric corrosion. The pentoxide is used as an oxidizing catalyst in the conversion of naphthalene to phthalic anhydride and in place of platinum in the modified contact process of manufacturing sulphuric acid. Indeed, in the latter process it is likely to supersede entirely the use of platinum. Compounds of vanadium are also used in the preparation of ink, in dyeing, as accelerators in the drying of paints and varnishes, in insecticides, photographic chemicals, in glass manufacture and therapeutic substances.

\section{Pharmacology}

Experimental poisoning in animals indicates similar symptoms to those observed industrially by Dutton (1911). These will be described in a later 
section. Daniel and Lillie (1938) found that cumulation does not occur and that acute and chronic symptoms are similar. They administered by mouth sodium meta- and ortho-vanadate to rats and noted immediate intense distress, haemorrhages from the nose and intestines, marked diarrhoea, paralysis of the hind legs, dyspnoea and convulsions. The post-mortem findings were those of acute desquammative enteritis.

D. E. Jackson's (1912) experiments concerned the circulatory effects of the intravenous injection of sodium orthovanadate. There was a rise in blood pressure due to systemic vaso-constriction by direct action on arterial muscle or vasomotor endings. The heart was not strengthened. The pressure in the pulmonary artery also rose by systemic and pulmonary vaso-constriction. Perfused lung vessels were strongly constricted. Bronchial muscle also showed moderate but prolonged constriction.

Luzzato (1903) showed that the effects of vanadium chloride and bromide are the usual lesions of a metal in the kidneys, liver, stomach and intestines. He found no lesions in the central nervous system. The blood pressure was raised and the excitability of the vagus depressed. Death occurred from respiratory failure.

Fischer (1934) recorded that ' in experimental poisoning of a more or less serious character, the mucous membrane of the eyes, nose and stomach becomes covered with a greenish coating containing vanadium.'

Levaditi (1928) investigated the spirochaetal value of vanadium on rabbits and Pereira (1939) carried out a clinical research with the same object. The latter injected vanadium sodium tartrate, $0.15 \mathrm{gm}$. in 2 c.c. of water, intramuscularly, twice a week. He reported prompt disappearance of spirochaetes, secondary lesions and gummata which had been refractory to bismuth and arsphenamine. He found it also effective in framboesia. The toxicity was low: stomatitis, erythema and hepatic disorders were rare sequels.

Sollman's (1942) views on the therapeutic uses of vanadium are less optimistic, for he states that ' the pharmacologic actions do not point to any definite therapeutic usefulness. Vanadium has been tried as an alternative similar to arsenic, in tuberculosis, diabetes, etc., but the results are not convincing. It was administered as sodium metavanadate, a white, almost tasteless powder, soluble in water. The dose used was 1 to $8 \mathrm{mgm}$. $\left(\frac{1}{60}\right.$ to $\frac{1}{8}$ grain).'

\section{Industrial Poisoning}

World consumption of vanadium more than trebled between 1936 and 1939. Poisoning from this source is, therefore, likely to be a factor of increasing importance (Fairhall, 1945). Dutton (1911) was the first to describe vanadium poisoning as he observed it in a plant in Carnegie, Pennsylvania where South American ore was used. He described a dry, irritating, paroxysmal cough, anaemia preceded by an increased red cell count, pallor, anorexia, emaciation, severe haemoptyses, albuminuria and casts, haematuria, fine tremours, failure of vision, vertigo, hysteria and melancholia as being the characteristic features. He found that tuberculosis was apt to supervene and that a fatal termination was not infrequent.

Hamilton (1943) has been unable to confirm Dutton's observations. She visited a plant where ferro-vanadium was manufactured from Peruvian ores by the alumino-thermite process and merely noted that the men suffered from a cough. At a mine in Colorado where the ore was found and then converted into sodium vanadate with salt, she was informed that the only hazard appeared to be chlorine which was liberated by the process. After precipitation with sulphuric acid, filtration and drying, the fine, sharp pointed crystals of sodium vanadate seemed to be very irritating to the nose, throat and bronchi. New men suffered most, from cough, but seemed to get acclimatized. Pneumonia was of the lobar type and was not noticeably prevalent. She had been informed of 'the complaint of twenty-two stevedores who were unloading Peruvian vanadium ore for only half a day and who insisted that the dust caused severe coughing which persisted through the night. There was, however, no time lost by these men.'

Symanski (1939) made a careful study of nineteen cases of vanadium poisoning which occurred among German metallurgical workers. He observed that only the workers themselves seemed cognizant of the health hazard. The effects appeared to be those of an acute irritant and were characterized by chronic bronchitis. With continued exposure specific infections might complicate the clinical picture. He recommended the mechanization and enclosure of all dusty processes.

The writer's experience extends to a period of nine years' observation of some 50 to 90 workers. At the present time about 50 persons are engaged, a dozen of whom are women. The latter are exposed to the same hazards as the men, but are more careful over personal hygiene and seem more resistant to vanadium poisoning. It should be added that women only came into this employment during the war years when mechanization began to displace the older, open, dusty methods. About 20 men have been engaged on the plant for periods in excess of eight years. As a class, they are paler and less robust in appearance than other process workers. The investigation of symptomatology was complicated by two factors: first, the presence of products of combustion of producer gas escaping into the department from the furnaces, a factor now in course of elimination, and secondly, the curious pride of workmen which impels them to exaggerate the risks of their occupation to new employees. It had been well known for some years that vanadium pentoxide dust caused bronchitis among the workers and efforts had been made to control the dust, but the full significance of the condition was not realized as the bronchitis always disappeared after an absence from the irritant of 
10 to 14 days and occasional skiagrams did not suggest anything worse than might be expected from, say, the inhalation of carbon dust. It was the observation of Dr. M. H. Jupe in the case of one vanadium worker (case 7 Plate 3 ) of the presence of reticulation which stimulated further investigation. Other cases of reticulation were found and also certain systemic effects tending to confirm Dutton's observations in 1911, observations which have been consistently controverted ever since. It will be noted that no expression of opinion is made here on the questions of anaemia and renal impairment, as systematic blood counts and examinations of centrifuged urinary deposits have not been performed. All that can be said at this stage is that the skin is usually pale, but there are no clinical signs of anaemia and that one man exhibited hyaline and granular casts in his urine. Also no opportunity for post-mortem examination has so far occurred and the underlying pathology of the radiological features is unknown.

(a) Dust reticulation and pneumoconiosis. These terms have assumed restrictive connotations since the work of Hart and Aslett (1942) on South Wales coalminers and these narrow interpretations have been confirmed in the Pneumoconiosis Regulations of 1943 with the exception that the aetiology has been extended to other dusts. Hart and Aslett offered the following definition: 'A dust-ridden state of the lungs corresponding to $\mathrm{x}$-ray reticulation, characterized by accumulation of silica and concommitant elaboration of reticular tissue throughout the framework of the lungs.' They considered the synonym 'anthracosis' to be unsuitable. The condition is due to the inhalation of coal-dust which contains a proportion of silica in its free and combined states; but whereas free silica causes nodulation and a minimum of reticulation, the predominance of silicates of the mica and clay types seems to cause reticulation and a minimum of nodulation. The carbon would appear to be a fortuitous factor. The pathology consists in a proliferation of reticulum fibres consequent upon the immobilization of dust cells in the intra-pulmonary lymphatics. It is not necessarily progressive. This definition, useful though it may be for certain purposes, is neither in lineal descent from Aschoff's conception of a vitally staining reticulo-endothelial system, nor is it strictly derivative from Maximow's histological classification of tissues forming an argyrophil, undifferentiated mesenchyme or syncytium. But what is more to present purposes is that it excludes similar radiological appearances due to substances other than dust containing coal and siliceous materials unless pulmonary fibrosis is a known concommitant.

But reticulation is a radiological appearance which is by no means restricted to the inhalation of carbonaceous and silicate dusts; indeed, it is often found among city dwellers as a class as well as in occupations exposing workers to certain other specific dusts. The first radiological phenomenon to be observed in all workers exposed to dusty processes is a continuation of the linear markings towards the peripheries of the lung fields. Whether this is due to fibrotic changes in the endopulmonary lymphatics or merely to shadows cast by the dust itself in these channels is generally a matter of opinion; undoubtedly the amount of fibrosis, if any, depends upon the character of the dust. As the perivascular lymphatics of the smaller vessels become involved in the process the lines seem to become interlaced and give the appearance of a network. Emphysema then occurs as a compensatory factor. Although no precise clinical phenomena distinguish the two stages, it may be stated generally that catarrhal features characterize the phase of increased linear striations and dyspnoea and a harsh and prolonged expiratory murmur accompany the more advanced stage. Vanadium workers complain of paroxysmal cough, chiefly troublesome on wakening, tenacious sputum very occasionally blood-stained and pains in the chest.

(b) Systemic intoxication. Although there are probably other dusts besides vanadium which cause reticulation of the lungs as well as systemic poisoning, at present the position of vanadium in these respects seems to be unique. Bronchospasm is commonly present and the blood pressure is frequently raised. These findings are in accord with the experimental work of Jackson. Palpitation on exertion, such as climbing a flight of stairs, is also consistent with Luzzato's (1903) observation that the irritability of the vagus is depressed. An accentuated second pulmonary sound which is occasionally found, seems to confirm the experimental evidence that the pressure in the pulmonary artery is elevated. Pallor of the skin, which is fairly characteristic, may be ascribed to the direct constricting action of vanadium on arterial muscle and myoneural junctions. No case of clubbing of the fingers or toes has been noted. Many exhibit a greenish-black discoloration of the tongue, more particularly men with septic teeth and furred tongues. Withdrawal from contact with the substance suffices to cause the disappearance of the discolouration in two to three days. It cannot be removed by cleaning and may be due to reduction of the pentoxide to the trioxide and formation of green salts by the actions of ptyalin and acid-forming bacteria in the mouth. It is probably evidence of exposure, rather than of intoxication (Case 9). The workman complains of a salty taste. Tremor of the fingers is fairly common in those workers with prolonged exposures, is fine, but may affect the arms and be so coarse as to interfere, for example, with the act of recording the blood pressure. Diarrhoea, anorexia, emaciation, visual defects, paralysis, vertigo, convulsions, hysteria and melancholia have not been observed. No case of tuberculosis has occurred, but three cases of lower lobe pneumonia (one fatal) and one case of middle lobe pneumonia are known. Workmen complain of frequent attacks of coryza. 


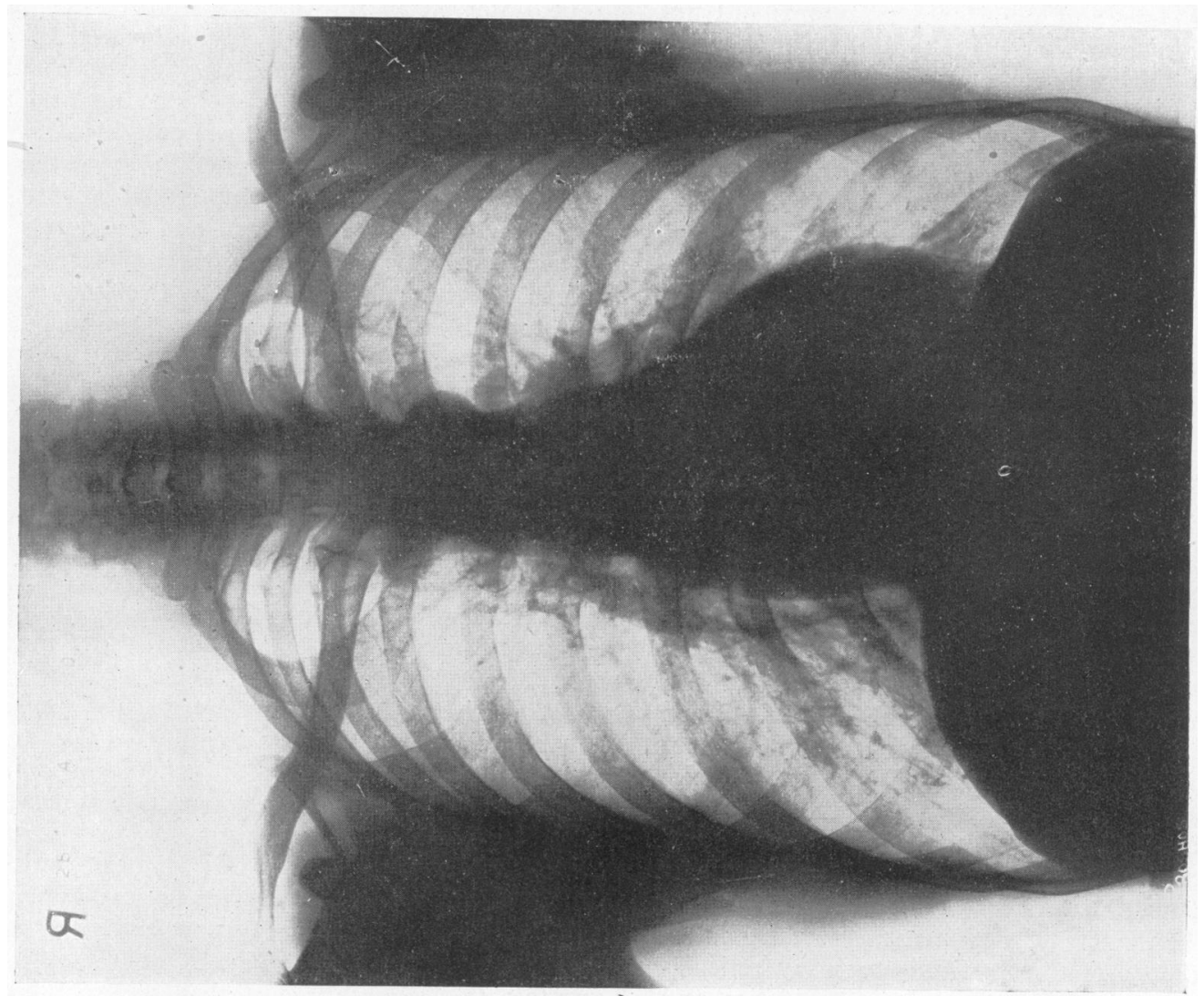

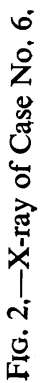
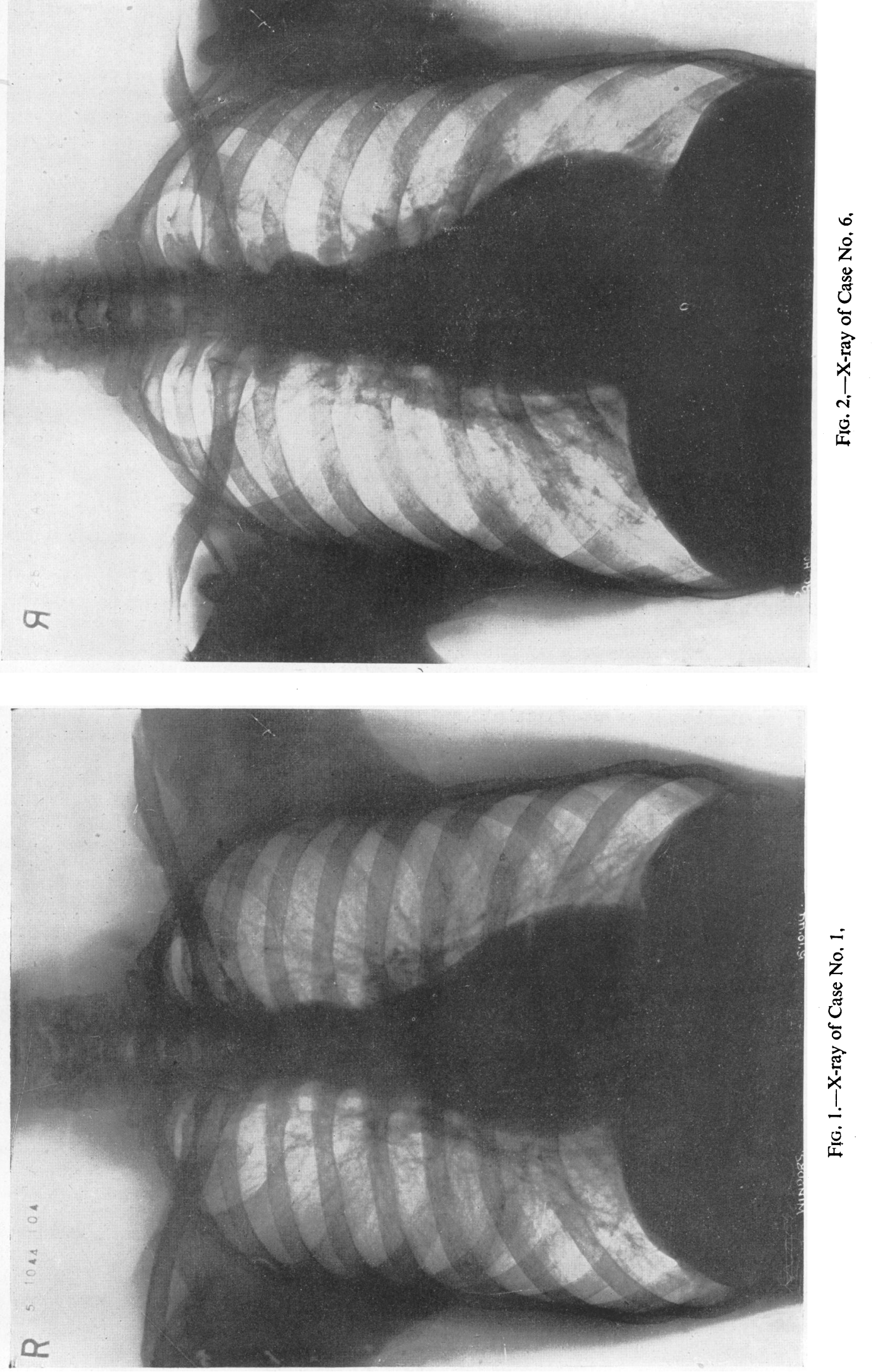


\section{Illustrative Cases}

Case 1. A. H. W., male, aged 30. Vanadium worker 1938 to 1946 . He complained of cough, dyspnoea on exertion or whilst wearing a gas-mask. His weight on $30 / 3 / 38$ was 9 st. $11 \mathrm{lb}$., on $28 / 4 / 459$ st. $10 \frac{1}{2} \mathrm{lb}$. On examination, he had many rhonchi throughout his chest. X-ray showed increased linear striations (fig. 1).

Case 2. A. H., male, aged 45. Chargehand Vanadium Dept. 1930 to 1946 . He suffered from attacks of lobar pneumonia in 1937 and 1940 . He complained of cough and dyspnoea. On examination, he was found to have a typical emphysematous chest. There were râles of all kinds in all areas. He showed tremor of his hands. $X$-ray revealed increased linear striations.

Case 3. E. J. M., male, aged 63. Vanadium worker 1941 to 1944. He complained of cough, of the stuffy, bronchitic type, with pains in both sides of his chest, and foul-smelling, bloodstained, copious sputum. On examination $(24 / 6 / 42$ and $13 / 3 / 43)$ he had a few highpitched rhonchi at both bases. X-ray revealed no abnormality. He died of lobar pneumonia in 1944.

Case 4. C. A. R., male, aged 35 . Vanadium worker 1938 to 1945 and then transferred. No antecedent history of note. He developed a pneumonia of the right mid lobe on May 17, 1945, during which he appeared very toxic and was tender over his liver. His blood-pressure was 130/84. An effusion appeared at the right base which was absorbed satisfactorily. On recovery, the skiagram indicated reticulation in both mid lung fields.

Case 5. B. T. W. J., male, aged 53. Vanadium worker 1944 to 1946, engaged in emptying ore from bags into cannisters. He complained that Rhodesian ore (mainly $\mathrm{V}_{2} \mathrm{O}_{4}$ ) made his cough worse. In 1943 he had lobar pneumonia, and he had further attacks of pleurisy in March and July, 1945. On examination, he had many râles throughout both lungs and an accentuated pulmonary second sound. His blood pressure was $170 / 100$.

Case 6. J. P., male, aged 41. Vanadium worker 1935 to 1945 . He complained that he began to suffer from a paroxysmal cough about a month after his employment on vanadium and it continued all the time he was in the department, except when on holiday. Latterly, it was accompanied by severe and troublesome dyspnoea and sharp chest pains, particularly on coughing and deep breathing. His weight on $31 / 8 / 38$ was 9 st. $10 \frac{1}{4} \mathrm{lb}$.; on $22 / 5 / 439 \mathrm{st} .2 \frac{3}{4} \mathrm{lb}$. His blood pressure was $150 / 100$. He had an accentuated pulmonary second sound and scattered râles throughout both lungs. X-ray showed reticulation in left mid zone and right base. There was slight enlargement of the left ventricle (fig. 2).

Case 7. W. J. C., male, aged 38. Vanadium worker 1940 to 1946. No antecedent history of note. He complained of cough all the time he had been in the department. He sometimes felt a sharp pain in the region of left nipple on coughing or breathing deeply. Dyspnoea and a feeling of exhaustion commenced about March, 1943. Cough was mainly troublesome on rising, but sometimes on going to bed. His sputum did not come up easily, was whitish, tasteless and inodorous. He was seldom free from nasal catarrh. He had attacks of pleurisy in 1941. His weight on $2 / 11 / 39$ was 10 st. $5 \frac{1}{4} \mathrm{lb}$; ; $25 / 4 / 4610$ st. $\frac{1}{4} \mathrm{lb}$. On examination; he had a pale skin; the mucous membranes were, however, well coloured. His blood pressure was 148/94. He had an accentuated pulmonary second sound. There were many rhonchi throughout the chest. $\mathrm{X}$-ray showed reticulation (fig. 3 ).

Case 8, C. J. L., male, aged 61. Vanadium worker August, 1940 to May, 1941. He had a history of

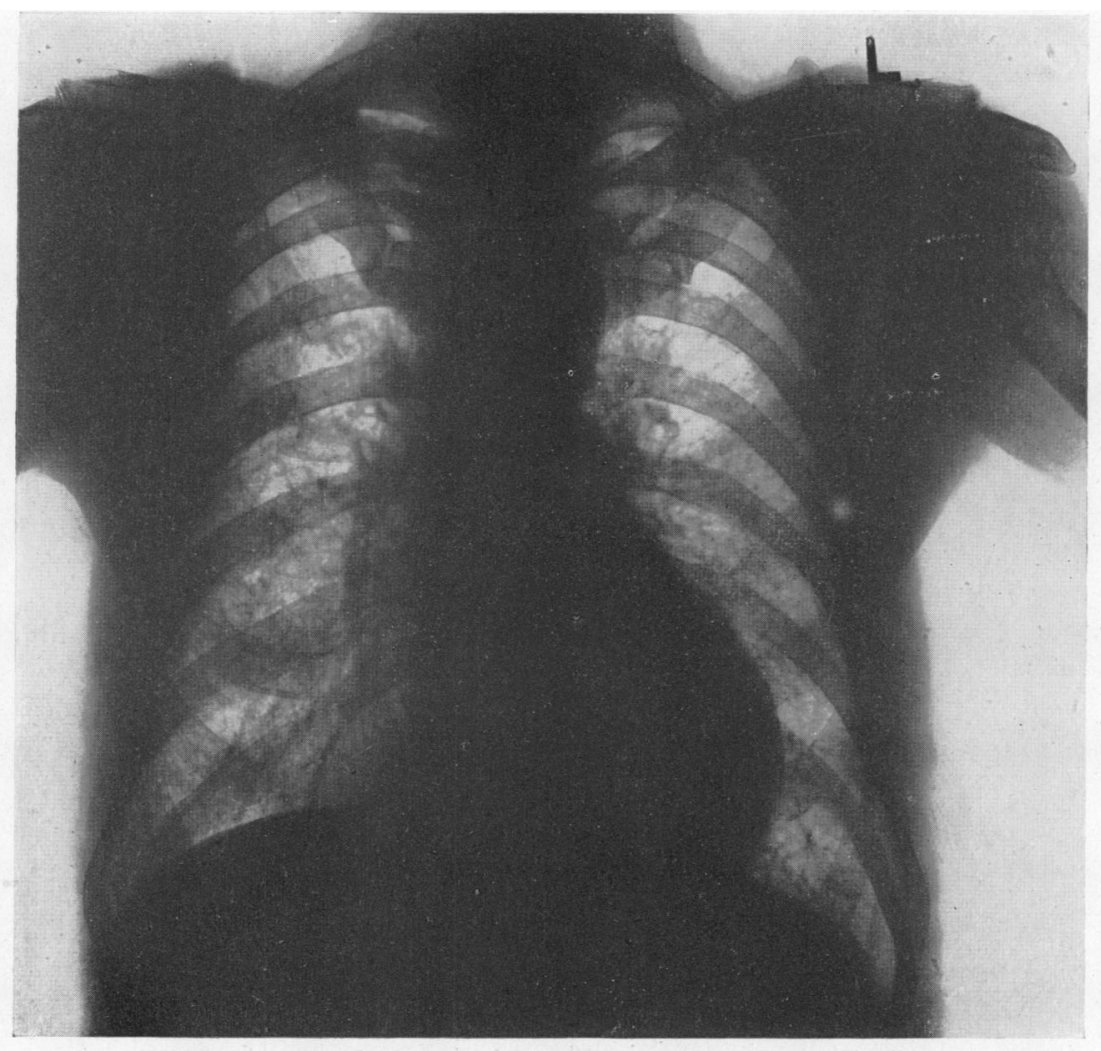

FIG. 3.-X-ray of chest of Case No. 7, showing reticulation. 
bronchitis since 1920. Dyspnoea became very severe during his exposure to vanadium dusts, improved considerably after transfer, but has recently returned. It was brought on by exertion such as walking. On examination, he had a typical emphysematous chest. There were râles of all kinds in all areas, and he had a harsh and prolonged expiratory murmur. His blood pressure was 140/94. X-ray showed reticulation in both upper lung fields and emphysema at the bases.

Case 9. M. J. R., male, aged 31. Vanadium worker for 5 months. He complained of cough for 4 months and a salty taste in mouth. He had a greenish-black tongue. His blood-pressure was $132 / 90$. There was no abnormal physical signs in his heart and lungs.

Case 10. C. R., male, aged 47. Vanadium worker 14 years. No antecedent history of note. He complained of paroxysmal cough chiefly on rising, but also on retiring. He coughed up tenacious, grey, tasteless, inodorous sputum, and had a salty taste in his mouth. Dyspnoea at end of shift was sometimes extreme and he had to lie down. He always had difficulty in getting home for the same reason. His chest felt tight, and there was palpitation on exertion, such as going up a flight of stairs. On examination, he had a greenish-black tongue. His blood pressure was $120 / 80$. He had a coarse tremor of both hands. There were many rhonchi throughout both lungs.

\section{Summary}

An industrial disease is described with the unusual combination of dust reticulation and systemic intoxication. The observed features of the syndrome associated with industrial exposure to vanadium pentoxide are : (1) pallor of the skin, (2) greenish-black discoloration of the tongue, (3) paroxysmal cough, rarely with haemoptysis, (4) dyspnoea, (5) pains in the chest, (6) palpitation on exertion, (7) tremor of the fingers and arms, (8) barrelshaped, emphysematous chest, (9) profuse bronchitis, (10) bronchospasm, (11) raised blood pressure, accentuated pulmonary second sound, and (12) reticulation on X-ray examination. It seems likely that colds and pneumonia are of more frequent occurrence than in the general population.

Ten case histories are briefly reproduced.

\section{Acknowledgements}

I am grateful to Messrs. Murex, Ltd., for giving the facilities to observe this condition and for their encouragement throughout the work. I have to thank Dr. M. H. Jupe for permission to publish the X-ray of Case 7.

\section{REFERENCES}

Ballotta, F. (1935). Biol. Abst., 9, 346.

Daniel, E. P., and Lillie, R. D. (1938). U.S. Pub. Hlth. Repts., 53, 765.

Dutton, W. F. (1911). J. Amer. Med. Assn., 56, 1648.

Fairhall, L. T. (1945). Physiol. Rev., 25, 195.

Fischer, R. (1934). Occupation and Health, Geneva, 2, 1177.

Hamilton, A. (1934). Industrial Toxicology, 3rd edition, New York, p. 107.

Hart, P. D., and Aslett, E. A. (1942). Spec. Rep. Ser. Med. Res. Coun. Lond., No. 241, p. 221

Jackson, D. E. (1912). J. Pharmacol. and Exper. Therap., 4, 1.

Levaditi, C., Lepine and Schoen(1928). Compt. rend. Acad.d. sc. 187, 434.

Luzzato, R. (1903). Arch. de farm. e terap., Palermo, 11, 42.

Parkes, G. D., and Mellor, J. W. (1939). Mellor's Modern Inorganic Chemistry, p. 759.

Pereira, J. (1939). Ltschr. f. Immunitatsforsch. u. exper. Therap.,

Sollman, 77. (1942). A Manual of Pharmacology, W. B. Saunders Co., Philadelphia, 6th edition, p. 1047.

Symanski (1939). Arch. Gewerbepath. u. hyg., 9, 295.

S. R. \& O., The Pneumoconiosis (Benefit) Scheme (1943), No. 886. 